\title{
Addictive potency of substances
}

\begin{abstract}
This article offers evidence supported by animal and clinical studies to propose that the addictive potency of a substance can be predicted based upon its properties: latency, euphoric potency, and half-life elimination and withdrawal effects. The correlations in which addictive potency vary with crucial influences were reviewed. Observations also suggests it is possible to predict the addictive potency of a substance by a mathematical formula of $\mathrm{A}=\mathrm{L} \times \mathrm{T}$ where A represents $\mathrm{L}$ represents latency and $\mathrm{T}$ Is elimination half-life.
\end{abstract}

Perspective: This article presents the crucial properties which determine the addictive potency of various chemical substances. Our insights could potentially help clinicians with better informed decisions when prescribing controlled substances.

Keywords: addiction, addictive potency, dependence, latency, withdrawal symptoms
Volume 2 Issue 4 - 2015

\section{Alen J Salerian}

Neuroscience Institute, USA

Correspondence: Alen J Salerian, Neuroscience Institute, 8409 Carlynn Dr., Bethesda, MD 208I7, USA, Tel 30I-204-9004, Email alensalerian@Gmail.com

Received: June 29, 2015 | Published: July 17, 2015

\section{Introduction}

Psychoactive substances have been part of human existence since antiquity and known for their mood altering and addictive properties. Many psychoactive substances such as nicotine, cocaine, marijuana, caffeine etc. are natural plant products and accessible to people.

The Diagnostic and Statistical Manual of Mental Disorders specifies a group of substance related disorders which includes typical drugs of abuse as well as some psychoactive medications that have abuse potential ${ }^{1}$ Within the category of substance related disorders are two general disorders: substance dependence and substance abuse ${ }^{1}$ The controlled substances act of 1970 established a system to classify substances with abuse potential (heroine mescaline and marijuana for instance are schedule one drugs with the highest that the potential whereas cocaine morphine and amphetamines are classified as a schedule two $)^{2}$ (Table 1).

Table I Controlled substances act schedule

\section{Schedule description}

Substances that have no accepted medical use in the US and have a high abuse potential

Substances that have a high abuse potential with severe sidekick or physical dependence liability

Substances that have an abuse potential less than those in schedule 2 including compounds containing limited quantities of certain narcotics and non-narcotic drugs

Substances that have and the abuse potential than those in schedule 3

Substances that have an abuse potential less than those in the schedule 4
Representative substances

Heroine LSD mescaline marijuana

Opium morphine meperidine cocaine amphetamines methylphenidate PCP

Paregoric barbiturates other than those listed in another schedule

Phenobarbital diazepam chloral hydrate alprazolam 
In general many factors including latency before euphoric effect, elimination half-life, speed and amount of intake and route of administration seem to be important for addictive properties of various substances. The purpose of this review is to determine whether addictive potency of a substance can be estimated by its latency and half elimination life: the shorter the latency and the halflife elimination the greater its addictive potency.

\section{Methods}

We will review correlations in which addictive potency of substances vary with latency and half-life elimination. The correlations between addictive properties and diverse influences that contribute to addictive properties will be examined under the following headings:
i. Animal studies
ii. Review of medical evidence

\section{Results}

\section{Animal studies}

Animal studies have elucidated various effects of addictive substances. Although animal and human responses cannot be viewed as identical animal studies are of importance to predict human responses. Below is a synopsis of major observations:

i. Opiates seem to both activate and inhibit dopaminergic activity. ${ }^{3}$

ii. Opiates acutely dampened dopaminergic activity whereas chronic treatment reverses its inhibitory influence. ${ }^{3}$

There are significant differences between the self administrations of opiates versus cocaine. Those self administering heroine maintained grooming behavior pretesting body weight in a good state of general health whereas rats self administering cocaine tend to cease grooming behavior, lose up to $47 \%$ of their pretesting body weight and experience profound deterioration in general health. ${ }^{4}$

i. The increase in self administration of opiates is not infinite and corresponds to a specific pattern. The animal self administers morphine just a sufficient amount to prevent discomfort associated with withdrawal symptoms. ${ }^{5}$

ii. Morphine micro injections into the ventral tegmental area of the midbrain produces dopaminergic activation of the meso limbic pathway consistent with conditions place preference and reduction of threshold for intracranial electrical self-mutilation. ${ }^{6}$

iii. Bioengineered mice that had become dependent on morphine like substances may still benefit from the analgesic effect yet not experience any withdrawal symptoms upon the discontinuation of the substance. A study by Basile and colleagues compared genetically normal mice with mutant mice in which the M5 receptor gene had been inactivated. Loss and five receptor function reduced withdrawal symptoms in mice that were dependent on morphine but it had no effect on morphine induced analgesia. These findings are consistent with the observation that M5 muscarinic receptors selectively influence the addictive properties of opiates. This further supports the critical influence of withdrawal symptoms in the genesis of addiction. ${ }^{7}$

iv. Review of medical evidence suggests several psychobiological mechanisms influence substance addiction. Evidence suggests that positive reinforcement mechanism is mediated by pleasure and reward pathways of dopaminergic activation. There is also solid research to serve the validity of a positive correlation between the euphoric and addictive potency over substance. It is also true that there is a linear relationship between $\mathrm{C}$-Max (maximum concentration of a substance) and Tmax (time to reach maximum concentration) and the euphoric effect.

Various studies reveal withdrawal responses also mediate addictive behavior. Physiological responses to withdrawal from opiates -morphine like substances can be described the following way. Soon after the discontinuation of morphine like substances a constellation of symptoms defined and is morphine abstinence syndrome develops. Most of the symptoms slowly emerge in the first 24 hour gradually resolving within 7 to 10 days from the onset of withdrawal. The symptoms include increased anxiety, restlessness, irritability, dilated pupils, gooseflesh, hot flashes, vomiting, diarrhea, fever, elevated blood pressure, increased heart rate, abdominal and generalized muscle cramps. Morphine abstinence syndrome seems to represent increase noradrenergic parasympathetic input the liturgical activity. The emergence of withdrawal symptoms coincides with plasma concentration half-life and total clearance of a morphine like substance.

In general medical findings can be summarized by stating that four factors seem to influence the addictive properties of various substances

\section{i. Euphoric potency \\ ii. Latency before effect \\ iii. Withdrawal symptoms \\ iv. Elimination half-life}

In general it can be observed that there is a negative correlation between latency and euphoric potency of a substance. The shorter latency the greater the euphoric effect. There seems to be a similar negative correlation between elimination half-life and withdrawal symptoms. The shorter the half-life the more intense withdrawal. In summary it can be hypothesized that a substance with the shortest latency and the shortest half-life elimination would be most addictive. Interestingly this hypothetical model match two previously proposed subjective rating scales (Henningfield-Benowitz and Salerian). ${ }^{8}$

The above observations can be mathematically expressed by the following equation: $\mathrm{A}=\mathrm{L}$ xT with A representing addictive potency $\mathrm{L}$ representing latency in hours and $\mathrm{E}$ representing elimination half-life in hours.

\section{Example}

Tobacco $0.1 \times 0.1=0.01$

Methadone $0.5 \times 72=36$

Cocaine $0.1 \times 0.1=0.01$

Oxycodone $0.25 \times 3=0.75$

Alcohol $0.1 \times 0.3=0.03$

Amphetamine salts $0.1 \times 10=1$ in essence in the above small sample the smallest numbers (tobacco and cocaine) would represent the most addictive substances. (Please see Table 2 which includes all major drugs with addictive potential). Interestingly and of significance the results of this mathematical model match very well two previously proposed subjective rating scales ( Henningfield-Benowitz and Salerian). ${ }^{8}$ 
Table 2:Addictive Potency*

\begin{tabular}{|c|c|c|}
\hline Substance & $A=L x T$ & $\begin{array}{l}\text { Addictive } \\
\text { Potency }\end{array}$ \\
\hline I. Cocaine (inh) & $0.01 \times 0.2$ & 0.002 \\
\hline 2.Tobacco & $0.01 \times 0.3$ & 0.003 \\
\hline 3. Alcohol & $0.01 \times 0.3$ & 0.003 \\
\hline 4. Heroine (IV) & $0.01 \times 1.5$ & 0.015 \\
\hline 5. Morphine (IV) & $0.01 \times 2.5$ & 0.025 \\
\hline 6. Morphine (PO) & $0.1 \times 2.5$ & 0.25 \\
\hline 7. Oxycodone (po) & $0.1 \times 3$ & 0.3 \\
\hline 8. Alprazolam & $0.1 \times 3$ & 0.3 \\
\hline 9. Methylphenidate & $0.1 \times 3$ & 0.3 \\
\hline $\begin{array}{l}\text { I0.Oxycodone (long- } \\
\text { acting) }\end{array}$ & $0.1 \times 8$ & 0.8 \\
\hline II.Amphetamines & $0.2 \times 10$ & 2 \\
\hline $\begin{array}{l}\text { I2. Methylphenidate (long- } \\
\text { acting) }\end{array}$ & $0.2 \times 10$ & 2 \\
\hline 13. Diazepam & $0.2 \times 24$ & 4.8 \\
\hline 13. Methadone & $0.2 \times 48$ & 9.6 \\
\hline $\begin{array}{l}\text { 14. Heroine (im long- } \\
\text { acting) }\end{array}$ & $0.2 \times 360$ & 72 \\
\hline
\end{tabular}

\section{Discussion}

Diverse substances of diverse chemical structures seem to contribute to addiction by specific biological properties which determine their addictive potency. Among many factors euphoric potency, latency withdrawal symptoms and elimination half-life seem to be influential for addictive effect. Based upon the available data it is possible to conceptualize a mathematical formula $(\mathrm{A}=\mathrm{LxT})$ to define the addictive potency of a substance. A mathematical equation does not preclude crucial psychosocial influences that mediate addictive patterns and behavior. For addiction is a complex human disorder to in diverse psychosocial and biological factors. This is precisely why this mathematical formula can only measure the relative addictive biological potency of a substance. Complex negative or positive societal or environmental influences will dampen or promote the biological addictive potency of any substance.

The limitations of these hypotheses are its theoretical nature and lack of prospective experimental substantiation. However of significance the hypotheses are based upon experimental findings and very closely match previous data. A scientifically and psychosocially relevant implication of these hypotheses is the observation that it clashes with current classification of the Schedule of Controlled Substances (Table 1).

\section{Conclusion}

Neuro-scientific observations are consistent with the conclusion that addictive potency of a substance is determined by four factors including latency, mood altering potency and elimination half-life and withdrawal effects. It is proposed that a mathematical formula of $\mathrm{A}=\mathrm{L}$ x $\mathrm{T}$ (where A represents addictive potency $\mathrm{L}$ represents latency and $\mathrm{T}$ is elimination half-life) may predict the addictive potency of a substance.

\section{Acknowledgements}

None.

\section{Conflict of interest}

The author declares no conflict of interest.

\section{References}

1. The Diagnostic Statistical Manual Of Psychiatric Disorders. USA: American Psychiatric Association Washington DC; 2014.

2. Physicians' Desk Reference. New Jersey PDR; 2015.

3. Meyer JC, Quenzer LF. Psychopharmacology Sinauer Associates; 2005.

4. Shippenberg TS, HERZ Spansgel. Neural substrates motivational effects of opiates. Biological psychiatry. 1991.

5. Woods JH, France CP, Bertalmio AJ, et al. Book your abuse liability assessment in rhesus monkeys. In: HerZz A et al. editors. Opioids 2 handbook of experimental pharmacology. New York, USA: Springer publisher; 1993. p. 609-632.

6. Bozarth MA, Wise RA. Toxicity associated with long-term intravenous heroine and cocaine self administration in the rat. JAMA. $1995 ; 254(1): 81-83$.

7. Basile AS, Fedorova I, Zapata A, et al. Deletion of the M5 muscarinic acetylcholine receptor attenuates morphine reinforcement and withdrawal but not morphine analgesia. Proc Natl Acad Sci USA. 2002;99(17):11452-11457.

8. Salerian AJ. Addictive potential. Med Hypotheses. 2010;74(6):10811083. 